\title{
A presença de possíveis relações homoafetivas na arte rupestre do Parque Nacional Serra da Capivara/PI, Brasil
}

The presence of homoafective relationships in the rupestre art of Serra da Capivara National Park/ PI, Brazil

DOI: $10.20396 /$ rhac.v2i2.14801

MICHEL JUSTAMAND

Docente da Universidade Federal de São Paulo - UNIFESP.

(D) 0000-0001-6944-5890

VITOR JOSÉ RAMPANELI DE ALMEIDA

Doutorando em Planejamento e Gestão do Território - UFABC. Docente da Fundação Escola de Comércio.

(D) $0000-0001-8470-2672$

GABRIEL FRECHIANI DE OLIVEIRA

Docente da Secretaria de Educação do Estado do Piauí - SEDUC/PI.

(D) 0000-0003-3528-2944

ANTONIEL DOS SANTOS GOMES FILHO

Docente do Centro Universitário Vale do Salgado - UniVS.

(D) $0000-0003-2230-4315$

VANESSA BELARMINO DA SILVA

Arqueóloga pela Universidade Federal do Vale do São Francisco - UNIVASF.

(D) 0000-0002-1973-6830

LEANDRO PAIVA

Mestrando em Antropologia Social - PPGAS/UFAM.

(I) 0000-0002-6135-4051

GIOVANNA NEIVA LUZ

Arqueóloga pela Universidade Federal do Piauí - UFPI.

(D) 0000-0002-5803-5308

MATTEUS FREITAS DE OLIVEIRA

Docente do Instituto Federal de Alagoas - IFAL.

(D) $0000-0002-4103-187 \mathrm{X}$ 


\title{
Resumo
}

Este artigo tem por finalidade abordar a presença de relações homoafetivas nas representações de arte rupestre no Parque Nacional Serra da Capivara, que está localizando no estado do Piauí. Estas relações homoafetivas são demonstradas a partir de um universo imagético da arte rupestre na região, onde é possível observar nessas representações interações sexuais entre imagens do gênero feminino entre si e imagens do gênero masculino entre. Destarte, para a construção desta hipótese foi utilizado o referencial teórico e metodológica das professoras Niède Guidon e Anne-Marie Pessis em conjunto com outros autores e baseado na pesquisa de campo.

Palavras-chave: Parque Nacional Serra da Capivara. Pinturas Rupestres. Relações Homoafetivas. Arqueologia.

\begin{abstract}
This article aims to address the presence of homo-affective relationships in rock art representations in the Parque Nacional Serra da Capivara, which is located in the state of Piauí. These homoaffective relationships are demonstrated from an imagery universe of rock art in the region, where it is possible to observe in these representations sexual interactions between female images and male images among themselves. Thus, for the construction of this hypothesis, the theoretical and methodological framework of professors Niède Guidon and Anne-Marie Pessis was used in conjunction with other authors and based on field research.
\end{abstract}

Keywords: Parque Nacional Serra da Capivara. Rock paintings. Homoaffective Relationships. Archeology. 


\section{Introdução}

Neste artigo apresentamos registros rupestres localizados no Parque Nacional Serra da Capivara (PNSC), no sudoeste do Estado do Piauí, que retratam possíveis cenas de relações sociais e sexuais entre pessoas do mesmo sexo e de outras temáticas relevantes ao assunto. Juntamente com a apresentação das cenas, registradas durante pesquisas de campo nos sítios arqueológicos do PNSC, realizamos sua apreciação fundamentadas nos referenciais teóricos desenvolvidos pelas professoras Niède Guidon, AnneMarie Pessis e Gabriela Martin, juntamente com estudos em arqueologia e antropologia que dialogam com as teorias e estudos da crítica feministas e LGBTQIA+, alinhadas ao debate de Arqueologias Queer e de Gênero, tais como Loredana Ribeiro² , Fabiano Gontijo e Denise Schaan ${ }^{3}$, Violet Baudelaire Anzini ${ }^{4}$ S Shay de los Santos Rodriguez ${ }^{5}$.

O PNSC tem sido local de pesquisas e reflexões sobre a presença humana ancestral e suas produções técnico-científicas e sociais desde os anos 1970, do século XX. Tal investimento científico se iniciou com a Missão Francesa, liderada, à época, pela arqueóloga Niède Guidon, com apoio de outros investigadores $\left(G U I D O N^{6}\right)$. Na região, foram, e continuam sendo realizados inúmeros trabalhos arqueológicos, paleontológicos, educacionais e ambientais, entre outros. Logo, compreende-se que este espaço socioambiental ainda reserva muitas descobertas para a ciência brasileira e mundial. Dada sua importância, o parque recebeu o reconhecimento da comunidade acadêmica graças às pesquisas arqueológicas realizadas, especialmente quanto às artes rupestres - principalmente, as pinturas. Essas pesquisas acabaram por colaborar com a elevação do PNSC à categoria de Patrimônio da Humanidade, em 1991, reconhecido pela Organização das Nações Unidas para a Educação, a Ciência e a Cultura-UNESCO7.

\footnotetext{
${ }^{1}$ Concordando com Ribeiro (2017a, 2017b), Gontijo e Schaan (2017) e Anzini (2020), compreendemos que não existe um pensamento feminista único nas ciências humanas e, tão pouco, disseminado nos movimentos sociais de luta e resistência. A singularidade ligada ao termo estudo feminista foi ampliada para a compreensão de múltiplos feminismos, no plural, desde os estudos de Scott (1990). As contribuições de feministas negras, lésbicas, latinas, queer e indígenas, como Conzalez (1988), Butler (2003), Lugones (2014) e Costa (2014) abrem espaço para uma crítica feminista aliada aos estudos culturais, fenomenológicos e com forte presença da descolonialidade.

2 RIBEIRO, Loredana; SILVA, Bruno. S. R.; SCHIMIDT, Sarah. K. S.; PASSOS, Lara. P. A Saia Justa da Arqueologia Brasileira: mulheres e feminismos em apuro bibliográfico. Estudos Feministas, v. 25, n. 3, 2017; RIBEIRO, Loredana. Crítica Feminista, Arqueologia e Descolonialidade: sobre resistir na ciência. Revista de Arqueologia, v. 30, n. 1, p. 210-234, 2017.

${ }^{3}$ GONTIJO, Fabiano de S.; SCHAAN, Denise Pahl. Sexualidade e Teoria Queer. Revista de Arqueologia, v. 30, n. 2, p. 51-70, dez. 2017.

${ }^{4}$ ANZINI, Violet Baudelaire. O poder das coisas: Corpa, falocentrismo, transgeneridade e Arqueologia. Revista discente de Arqueologia. Rio Grande, v. 1, n. 1, jul./dez. 2020.

${ }^{5}$ RODRICUEZ, Shay de Los Santos; ANZINI, Violet Baudelaire. Transviades contra o cistema transfóbico: você sabe o que é genitalismo? Revista Brasileira de Estudos da Homocultura, v. 3, n. 12, p. 41-57, 5 abr. 2020. Disponível em: https://periodicoscientificos.ufmt.br/ojs/index.php/rebeh/article/view/12026. Acesso em: 20 mai. 2021.

${ }^{6}$ CUIDON, Niède. Peintures préhistoriques du Brésil: l'art rupestre du Piauí. Paris: Editions Recherches sur les civilisations, 1991.

${ }^{7}$ PESSIS, Anne-Marie. Imagens da pré-história. São Raimundo Nonato: FUMDHAM/Petrobrás, 2003.
} 
O parque e sua circunvizinhança são ricos em vestígios arqueológicos e paleontológicos ${ }^{8}$. O PNSC toma maior importância se mencionados os sítios que apresentam as interações entre homem-megafauna, que como aponta Beló", são raros tanto no Brasil como em países da América do Sul, sendo o sítio da "Toca da Janela da Barra do Antonião" que abriga significativo registro dessa relação. Os vestígios arqueológicos de grupos humanos ancestrais, suas produções cerâmicas e materiais líticos - pedras lascadas e polidas, e seus registros comunicativos e artísticos compõem os diversos sítios arqueológicos do PNSC.

O desenvolvimento das pesquisas científicas no PNSC são motivos da maior disputa arqueológica dos últimos anos nas Américas, porque apontam para o povoamento em terras brasilis muito anterior ao que se poderia supor/imaginar em pesquisas anteriores ${ }^{10}$. Independentemente das polêmicas dos materiais líticos encontrados, as pinturas rupestres são os vestígios dos humanos ancestrais que aparecem em abundância e que se destacam aos olhos de qualquer habitante local, turistas e pesquisadores/as, sendo observadas nas rochas representações das caçadas, lutas, rituais religiosos, relações sociais e os mais variados tipos de relações sexuais. ${ }^{11}$

Frente a essa diversidade de artefatos arqueológicos, no presente estudo usaremos como fonte principal as pinturas rupestres que tratam sobre a temática da sexualidade humana ancestral e suas múltiplas práticas sociais, com ênfase a possível relação homoafetiva, inscritas nas rochas do PNSC ${ }^{12}$. As ideias de análise sobre esse tema surgiram a partir da expedição científica, realizada entre os dias 25 de janeiro e 2 de fevereiro de 2018, no PNSC, onde foram observadas e registradas diversas pinturas rupestres, nos 51 sítios visitados.

Destaca-se que esses locais foram escolhidos previamente e com cuidado, visando a obtenção da experiência interpretativa que se difere, metodologicamente, dos trabalhos quantitativos e classificatórios

\footnotetext{
${ }^{8}$ QUEIROZ, Albérico N.; PEREIRA, A. M. R.; OLIVEIRA, Gabriel F.; JUSTAMAND, Michel; SANTOS JUNIOR, Valdeci; ALMEIDA, Vitor ]. R. O pampatherium SP, nas pinturas rupestres do Parque Nacional Serra da Capivara - PI, BRASIL. Revista Interdisciplinar Encontro das Ciências, v. 3, p. 1013-1023, 2020.

${ }^{9}$ BELÓ, Pétrius da Silva. Alterações antrópicas em restos fósseis da megafauna: tafonomia do sítio arqueológico e paleontológico "Toca da Janela da Barra do Antonião", área arqueológica do Parque Nacional Serra da Capivara, Piauí, Brasil. Dissertação (Mestrado em Arqueologia) - Programa de Pós-Graduação em Arqueologia, Universidade Federal de Pernambuco, 2012.

${ }^{10}$ ETCHEVARNE, Carlos. A ocupação humana do nordeste brasileiro antes da colonização portuguesa. Revista da USP, São Paulo, n. 44, p. 121-141, dez./fev., 1999-2000. ADOVASIO, James M.; PAGE, Jake. Os primeiros americanos. Em busca do maior mistério da arqueologia. Trad. Renato Bittencourt. Rio de Janeiro: Record, 2011.

${ }^{11}$ MELTZER, David; ADOVASIO, James M.; DILLEHAY, Tom D. Uma visão da Toca do Boqueirão da Pedra Furada. Fundhamentos - Revista da Fundação do Museu do Homem Americano, São Raimundo, v. 1, n. 1, p. 347-377, 1996. JUSTAMAND, M.; FUNARI, P. P. A.; ALARCÓN-JIMÉNEZ, A. Arqueologia da sexualidade: representações das genitálias femininas e masculinas nas pinturas rupestres no Parque Nacional Serra da Capivara/PI. Embu das Artes: Alexa Cultural, 2016.

12 COMES FILHO, Antoniel dos Santos; JUSTAMAND, Michel. Registros rupestres do Parque Nacional Serra da Capivara-Piauí: breves reflexões sobre a pesquisa antropológica na educação e suas perspectivas interdisciplinares. Ciência e Sustentabilidade -CeS, Juazeiro do Norte, v. 4, n. 1, p. 39-56, jan./jun., 2018.
} 
da arqueologia como os anteriormente realizados por Guidon ${ }^{13}$ e Pessis et a $l^{14}$. Influenciados por estudar o amor, a violência e a solidariedade nas pinturas rupestres do PNSC, nos distanciamos da arqueologia anterior, a conquista em busca de gerar, nas fendas das representações do que entendemos como possíveis manifestações de sexualidades, subvertem olhares biologizantes, binaristas e heteronormativos. Nossa escolha objetivou reunir o maior número possível de cenas sexuais/sociais entre pessoas representadas do mesmo sexo ${ }^{15}$, que são pouco analisadas e/ou inéditas nas publicações acadêmicas.

Os diálogos entre pesquisadoras, pesquisadores e o condutor Mário Filho (credenciado para atuar no parque), contribuíram para sistematização do levantamento de informações e planejamento da atividade de campo. O auxílio do condutor no território do PNSC se tornou necessário porque, para além da dificuldade de circular dentro do parque, em virtude das suas dimensões, acidentes geográficos e perigos iminentes, como animais selvagens, as informações sobre a dimensão sentida e apreendida da paisagem, a partir dos diálogos no pré-campo, campo e pós campo, revelava para nós outra arqueologia do presente, diferente desta que nos desafia a entender as possíveis cenas sexuais, devido às limitações metodológicas para leituras temporais e contextuais tão emblemáticas para as ontologias do presente ${ }^{16}$.

As relações que atualmente concebemos como homoafetivas estão presentes nas cenas rupestres da Serra da Capivara, desafiando a manutenção de um sistema generificado e generificante que mantem um discurso naturalizador e atemporal da simetria entre sexo, gênero e sexualidades, desestabilizando o binarismo e os desejos heteronormativos que são reiteradas pelas instituições que governam os corpos de nossa era ${ }^{17}$. Vale salientar que a concepção da homoafetividade é uma acepção recente na história humana assentada em concepções médicas e da psiquiatria moderna.

Em estudo anterior, Colling et $a{ }^{18}$ sugerem uma perspectiva Queer para compreender os contextos presentes em pinturas rupestres. Para os autores, concordando com Gontijo e Schaan, existe uma armadilha interpretativa posta (e, por que não, imposta) ao visualizar as inscrições de povos ancestrais

\footnotetext{
${ }^{13}$ GUIDON, op. cit.

14 PESSIS, Anne-Marie; CISNEIROS, Daniela; MUTZENBERG, Demétrio. Identidades gráficas na arte rupestre: Parque Nacional Serra da Capivara. In: ALBUQUERQUE, Marleide Lins; BORGES, Síria Emerenciana Nepomuceno (orgs.). Identidades e diversidade cultural: Patrimônio arqueológico e antropológico do Piauí - Brasil e do Alto Ribatejo - Portugal. Coletânea. Teresina: FUNDAC - CEIPHAR/ ITM, 2013, p. 19-33.

${ }^{15}$ JUSTAMAND, M.; OLIVEIRA, G. F.; GOMES FILHO, A. S.; BELARMINO, V. S.; FUNARI, P. P. A. Female representations in rock art scenes, São Raimundo Nonato-PI, BRAZIL. Expression: quarterly journal, v. 1, p. 29-35, 2019.

${ }^{16}$ GONTIJO, SCHAAN, op. cit.

${ }^{17}$ Cf.: HARAWAY, Donna. Saberes localizados: a questão da ciência para o feminismo e o privilégio da perspectiva parcial. Cadernos Pagu, v. 5, p. 7-41, 1995. BUTLER, Judith. Problemas de gênero: feminismo e subversão da identidade. Rio de Janeiro: Civilização Brasileira, 2003. FOUCAULT, Michel. A História da Sexualidade: a vontade do saber. Volume 1. Paz e Terra, 2014. RODRIGUEZ, ANZINI, op. cit.

${ }^{18}$ COLLING, L.; JUSTAMAND, M.; COMES FILHO, A.; OLIVEIRA, G. F. Questões queer para analisar os registros rupestres com cenas que sugerem práticas sexuais na Serra da Capivara. Revista de Arqueologia (Sociedade de Arqueologia Brasileira. IMPRESSO), v. 32, p. 24-41, 2019.
} 
grafadas em rochas. Observamos constante risco em estabelecer simetrias entre um passado, cujos marcadores sociais, normas, valores, significados e significantes são para nós pouco inteligíveis em seu paleocontexto e são erroneamente interpretados por meio das lógicas dos simulacros do projeto de modernidade que atuam como cirurgias ideológicas para controlar nossas percepções, corpos, tempos e espaços, recriando realidades dominadas de ideologias a favor de uma concepção colonizadora.

Diante disto, Colling et a $1^{19}$ nos conduz a olhar, por meio de uma leitura tradicional, os sítios arqueológicos da Serra da Capivara, onde há mais de 1.300 sítios com cenas rupestres que remetem à possíveis cenas sexuais, datadas entre 6 e 12 mil anos, produzindo estranhezas e subversões ao discurso do conhecimento situado que acampa os grandes tratados arqueológicos a favor do binarismo e normatividade dos sexos, gêneros, e das sexualidades ${ }^{20}$.

Assim, o estudo tem como objetivo apresentar e analisar a presença de possíveis relações homoafetivas na arte rupestre do Parque Nacional Serra da Capivara - PI e interpretá-la para além da correspondência corpo-sexo-gênero-desejo-sexualidade em dois polos antagônicos e biologizados, evitando transportar a prisão discursiva que dominam os corpos de nossa era para uma leitura aprisionadas no campo da arqueologia subversiva queer ${ }^{21 .}$

O passado grafado nas paredes rochosas do PNSC, compõem fragmentos de uma paisagem aparentemente menos heteronormativos, em que os territórios obedeciam a outras lógicas de poder do qual o gênero, como hoje é compreendido, não era elemento fundador das relações sociais. Estas paisagens estão marcadas com cenas de sexo, o que podemos indicar, a partir da visão tradicional, como um grande manual de Kama Sutra da pré-história, com cenas de sexo grupal, pessoas entre pessoas do mesmo sexo, bestialismo/zoofilia entre outras expressões de práticas sexuais ${ }^{22}$. Esses registros nos remetem a pensar que as práticas atualmente conceituadas como homoafetivas são tão antigas quanto o próprio humano, confirmando algumas teorias sociocomportamentais de Freud.

Para Freud a homoafetividade não era uma doença, na verdade nunca o foi. O psicanalista a considerava uma variabilidade da função das formas sexuais, e reforça que a homoafetividade é uma

\footnotetext{
19 Ibidem.

${ }^{20}$ HARAWAY, op. cit

${ }^{21}$ FOUCAULT, Michel. Vigiar e punir: nascimento da prisão. Trad. Raquel Ramalhete. $24^{a}$ ed. Petrópolis: Vozes, 1987. Idem, op. cit., 2004

${ }^{22}$ COMES FILHO, Antoniel dos Santos; COLLING, Leandro; JUSTAMAND, Michel; OLIVEIRA, Gabriel Frechiane; BELARMINO, Vanessa da Silva; SANTOS FILHO, Mário R. Nossos ancestrais praticavam sexo? Diversidade sexual nos registros rupestres do Parque Nacional Serra da Capivara - PI, Brasil. Somanlu - Revista de Estudos Amazônicos, v. 18, p. 1-13, 2018. JUSTAMAND, M.; OLIVEIRA, G. F. de; FUNARI, P. P. A.; QUEIROZ, A. N. de; SANTOS, V. dos; GOMES, A. dos S.; ALMEIDA, V. J. R. de e SILVA, V. B. de. Multiplicidade sexual nos registros rupestres do Parque Nacional Serra da Capivara - PI (BRASIL). Somanlu - Revista de Estudos Amazônicos, v. 20, p. 71-92, 2020
} 
variabilidade polimorfa e quem tem isso é capaz de desfrutar de várias formas de prazer e desejos, que hoje a "sociedade" reprime de forma incoerente, o que não poderia aparecer nos tempos de pré-contato, assim as pessoas poderiam ser mais livres em suas manifestações sexuais.

Freud, ao que nos parece, via essas manifestações dentro da extrema normalidade, ou seja, para ele como o ser humano pode desenvolver suas fantasias sexuais livremente e isso com bastante naturalidade sem censura e sem julgamentos.

\section{As percepções atribuídas às pinturas rupestres: verdades construídas a favor de qual passado?}

Tratar das pinturas rupestres em Arqueologia e não pontuar o lugar de prestígio dessa temática no interior da disciplina, enquanto campo de pesquisa, é usar das ferramentas discursivas de dominação que mantém esta ciência com ares de materialidade/objetividade, em função da base positivista que sustenta sua formação enquanto saber sistematizado ${ }^{23}$.

Não é de interesse nosso realizar uma incursão epistemológica da evolução do pensamento arqueológico, mas revelar as intencionalidades de um saber situado, como discutiu Donna Haraway ${ }^{24}$ e reconhecer o papel instrumentalizador que a Arqueologia assumiu no projeto de Modernidade, sobre a produção da história do sentimento nacional no Brasil e a condução ideológica da colonização europeia para gerar uma falsa sensação de autonomia política, econômica, cultural e ideológica ${ }^{25}$.

As considerações feitas por Trigger ${ }^{26}$ e Ribeiro ${ }^{27}$ problematizaram o desinteresse de arqueólogos em desenvolver o campo de análise voltado para as pinturas rupestres, como temática subalterna, "inóspita e inabitável"28, de conhecimentos secundários destinados a serem produzidos por arqueólogas. Não diferente de outros campos acadêmicos, o projeto sexista, falocêntrico, eurocentrado encontrou terreno fértil na Arqueologia, delimitando espaços acadêmicos, atribuindo divisões sexuais em temáticas de pesquisa e mais que isso, produzindo um conhecimento com base no dimorfismo de gênero, sexista, machista, classista, racista, mulherofóbico, transfóbico e homofóbico.

\footnotetext{
${ }^{23}$ TRICGER, Bruce, C. História do Pensamento Arqueológico. $2^{\text {a }}$ Edição. Brasil: Odysseus, 2011. RIBEIRO, Loredana. Sobre pinturas, gravuras e pessoas - ou os sentidos que se dá à arte rupestre. Revista Especiaria - Cadernos de Ciências Humanas, Dossiê Arqueologia Hoje. Universidade Estadual de Santa Cruz, 2009. RIBEIRO et al, op. cit.; Idem, op. cit., 2017.

${ }^{24}$ HARAWAY, op. cit.

${ }^{25}$ COMES, op. cit.

${ }^{26}$ TRICCER, Bruce G. História do pensamento arqueológico. São Paulo: Odysseus Editora, 2004.

${ }^{27}$ RIBEIRO et al, op. cit., 2017

${ }^{28}$ BUTLER, op. cit.
} 
As pinturas e gravuras realizadas em suportes rochosos pelos povos indígenas do passado são consideradas uma evidência arqueológica de difícil trato acadêmico, pela dificuldade de datação e de associação com o restante do contexto arqueológico. Por este motivo, constituiu-se num tópico de menor interesse, tanto no Brasil quanto em outros países. Gozando de baixo status entre profissionais da arqueologia, as expressões rupestres passaram a ser consideradas foco de estudos menores já desde as últimas décadas do século passado. ${ }^{29}$

Na trama da geração de conhecimento, a Arqueologia impregnada de ranço positivista, engendrou a produção de um saber direcionado ao papel dominador de seres machos biologizados para recontar a histórias por meio dos achados arqueológicos. Surgem então, as retóricas disciplinares das instituições normatizadoras, que não moldaram apenas os corpos que Foucault ${ }^{30}$ interpretou como dóceis, mas reconstruiu espaços performáticos generificados a favor da norma heterossexual, branca, cristã, classe média, anglo-europeia e para além disso foi capaz, de nos escombros das escavações arqueológicas, recontar o passado com as lentes do projeto modernista em curso, produzindo verdades situadas a favor da matriz heteronormativa ${ }^{31}$.

O conhecimento generificado produziu na Arqueologia leituras anacrônicas, transportando levianamente o modus operandi da nova roupagem do modo de produção capitalista (incluindo as novas ressignificações realizadas para entender o corpo do homem e da mulher, a família e a propriedade privada, por exemplo) para interpretar, com tom de objetividade e materialidade (classificatória), as relações sociais, de uma outra forma de socialização, no contexto do pleistoceno.

O binarismo, que cirurgicamente atua com tecnologias sociais para modelagem dos corpos, inteligibilidade e discursos que emanam poder, contribuiu para territorialização de visão tradicional Cistêmicano que se refere a compreensão dos paleos espaços e paisagens povoados por nossos ancestrais. Essa visão reitera normas produzidas pela matriz heteronormativa como discutiu Rodriguez e Anzini ${ }^{32}$, mantendo a correspondência de desejos cis, sexo cis, sexualidades cis e, finalmente, cisgêneros.

Segundo, Ribeiro ${ }^{33}$, a missão Francesa e o PRONAPA reduziram as possibilidades de novos imaginários para compreender as pinturas rupestres, conduzindo metodologicamente a abordagem estruturalista, difusor cultural europeu, como ponto de partida aceitável - enquanto viés de análise, com

\footnotetext{
${ }^{29}$ RIBEIRO, op. cit., 2017.

${ }^{30}$ FOUCAULT, op. cit., 1987.

${ }^{31}$ GONTIJO; SCHAAN, op. cit.

${ }^{32}$ RODRIGUEZ, ANZINI, op. cit.

${ }^{33}$ RIBEIRO, op. cit., 2017
} 
base em tradições e estilos para compreender a composição de painéis rupestres. Um dos exemplos foi a posição radical assumida por Laming-Emperaire contra o comparativismo etnográfico na interpretação das artes rupestres. O trabalho de Martin ${ }^{34}$ sobre a temática amor, abre um novo caminho metodológico da pesquisa arqueológica no Brasil, ampliando possibilidades para compreensão de histórias, de significativa subjetividade, contidas nas pinturas rupestres e que precisam ser relevadas e discutidas ${ }^{35}$.

O trato arqueológico dado ao passado, cristalizado nas pinturas rupestres, ofereceu exclusividade a ação ancestral masculina, invisibilizando as dinâmicas referentes as produções femininas. Como foco dessa estratégia, muitos resultados de pesquisa privilegiaram cenas de caça, lutas, sacrifícios xamãs, descrição de fauna e flora, como saberes articulados, produzidos e registrados por ancestrais machos, portanto, com pênis, então homens. Temos aqui a elaboração do paradigma maior que conduziu, nos corredores do dimorfismo e binarismo de gênero, a masculinidade arqueologizada do caçador - guerreiro.

As cenas de possíveis relações eróticas entre ancestrais de mesmo sexo, o que a leitura tradicional indicaria homem com homem e mulher com mulher, são vestígios de um passado escandaloso que precisava ser mantido longe do debate acadêmico. E foi exatamente essa estratégia realizada pela arqueologia histórico-cultural. Este trabalho, portanto, vem escandalizar a centralidade machista que ocupa a cena do conhecimento arqueológico, pelas fendas que estão abertas do passado que nos possibilita novos imaginários de outros possíveis marcadores sociais distantes do que conhecemos como a matriz heterossexual fortemente atuante desde o século XVII ${ }^{36}$.

\section{Refletindo a partir de outros locais do mundo}

O fato de nos comunicarmos é, provavelmente, o maior motivo de estarmos vivos hoje. Assim, sem dúvidas nós somos amantes das palavras e diuturnamente as usamos na forma da fala e da escrita, indescritivelmente, sendo as palavras a maior fonte de expressar o que nos faz ser entendidos. Todavia, "muito antes de qualquer escrita, os que habitavam as grutas de Altamira comunicaram com seus semelhantes e se pode dizer que continuam a comunicar "demonstrando que a história dos humanos se comunicando teve seus primeiros registros amparados na imagem ${ }^{37}$.

\footnotetext{
${ }^{34}$ MARTIN, Gabriela. Amor, Violência e Solidariedade no Testemunho de Arte Rupestre Brasileira. Clio - Revista do Curso de Mestrado em História da Universidade Federal de Pernambuco, Recife, n. 6, 1984, p. 27-37.

35 JUSTAMAND et al, op. cit., 2019.

${ }^{36}$ FOUCAULT, op. cit., 1987; GONTIJO, SCHAAN, op. cit.

37 PELTZER, Gonzalo. Jornalismo iconográfico. Lisboa, Planeta, 1991.
} 
A arte ancestral, especialmente as grafadas em rochas, fornecem informações sobre o que os grupos humanos consideravam substancial em suas vidas e, de acordo com Justamand et a $a^{138}$ as particularidades das representações das cenas, sejam sociais ou não, são fontes arqueológicas e, também, antropológicas, históricas e geográficas. Nessas artes estavam contidas uma forma de reverência desses ancestrais aos poderes criativos da natureza e a autora sugere que faziam isso por meio das imagens sexuais e/ou de nascimentos ${ }^{39}$.

As cenas das pinturas rupestres se relacionam diretamente com os interesses múltiplos dos grupos usuários desejosos de comunicar, ensinar e transmitir conhecimentos e saberes acumulados ao longo do tempo para as gerações futuras ${ }^{40}$. Por isso, talvez, as figuras com conotações voltadas para a sexualidade tinham um papel importante, o que para a visão tradicional corresponde apenas a um aspecto fundamental da vida humana, no que se refere a sobrevivência e reprodução da espécie, é também para nós mediadora das relações sociais e individuais por meio das relações de poder como aponta os estudos de Contijo e Schaan ${ }^{41}$. Pensamos que o mesmo pode ter ocorrido com as cenas rupestres existentes no PNSC (ver Figura 1).

\section{Figura 01: Cena da Penetração com amamentação. Toca do Caldeirão dos Rodrigues, Parque Nacional Serra da Capivara - PI. Acervo dos autores.}

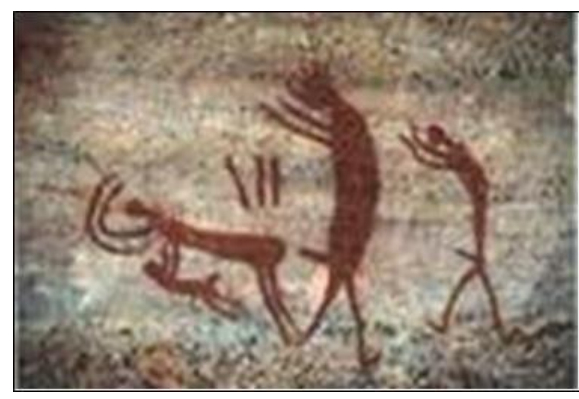

A temática da sexualidade é muito recorrente em inúmeras formas de expressão artísticas e culturais da humanidade, desde os tempos imemoriais. Como Eisler ${ }^{42}$ e Peter Stearns ${ }^{43}$ lembram que a arte primitiva tinha forte conteúdo sexual. Partilhamos as suas ideias de que a sexualidade do passado pode contribuir para entendermos e ou explicarmos a do presente, haja vista a quantidade de cenas voltadas às práticas sexuais

\footnotetext{
${ }^{38}$ JUSTAMAND et al, op. cit., 2020.

${ }^{39}$ EISLER, Riane. O prazer sagrado: Sexo, mito e política do corpo. Trad. Ana Luiza Dantas Borges. Rio de Janeiro: Rocco, 1996.

${ }^{40}$ BUCO, C. A.; OLIVEIRA, G. F.; JUSTAMAND, Michel; ALMEIDA, V. J. R.; COMES FILHO, A. S.; BELARMINO, V. S. O papel das mulheres ancestrais nas pinturas rupestres do Parque Nacional Serra da Capivara-PI, BRASIL. Revista Memória em Rede, $v$. 12 , p. 245-273, 2020.

${ }^{41}$ GONTIJO, SCHAAN, op. cit.

42 EISLER, op. cit.

${ }^{43}$ STEARNS, Peter N. História da Sexualidade. Trad. Renato Marques. São Paulo: Contexto, 2010.
} 
encontradas no PNSC (ver figuras 2 e 3), devido ao grande número de recorrências observados, destarte, a temática sexualidade é algo presente dentro do universo simbólico dos grupos humanos pré-coloniais ${ }^{44}$.

As diversas cenas encontradas no parque sejam elas de ordem sexual ou não, nos apontam para a observação do corpo humano, delineadas na pintura pela forma (antropomórfica). Como abaliza Justamand ${ }^{45}$ a cultura visual é expressamente corporal, que ora é marcado sexualmente, ora não. Esse ponto é importante para se pensar como nossos ancestrais se relacionavam socialmente. Como nos lembra o autor, em menção a Le Breton ${ }^{46}$, esse corpo ancestral é construído, e nos estudos sobre arte rupestre podemos apontar que este é reconstruído, nas interpretações contemporâneas.

Assim compreendemos que há uma questão latente que é como interpretar essas recorrências arqueológicas? A analogia direta não é uma resposta unilateral em função das descontinuidades do tempoespaço, é necessário observar as recorrências no registro rupestre, os vestígios arqueológicos diretos encontrados no local e tentar construir linhas interpretativas que entrelaçam o passado e o presente. Desse modo, podemos pensar o gênero enquanto um processo de construção sociocultural que é atravessado por normas (implícitas e explicitas) que regulam as relações humanas, inferindo diretamente nas formas individuais e coletivas de representação de si e do outro no e para o mundo ${ }^{47}$. Logo, o olhar sobre o gênero no que tange suas relações com as construções sociais, não é uma negação do biológico, mas o entendimento de que sobre nesse bio-corpo há práticas de regulação que são produtos da cultura ${ }^{48}$ sejam elas das sociedades modernas ou das sociedades pré-históricas.

Bem como todas as subdisciplinas da arqueologia, a arqueologia histórica também recebeu fortes influências das transformações teóricas que esta ciência antropológica e histórica sofreu ao longo de seus anos de formação. Assim, é importante salutar as escolas arqueológicas e seu desenvolvimento até chegar nas discussões de gênero.

Vamos iniciar com o pensamento histórico-culturalista, para o qual a cronologia e a espacialidade eram as principais inquietações desde o século XIX. Em seguida, passando pela incessante procura por entender o comportamento humano, ou seja, suas leis tão em voga pelos praticantes do processualismo ou nova arqueologia desde a década de 1960. E por finalmente, com o advento do pós-processualismo na década

\footnotetext{
${ }^{44}$ JUSTAMAND, M.; FUNARI, P. P. A. Sexual scenes in serra da capivara rock art, BRAZIL. Expression, v. 15, p. 26-35, 2017.

${ }^{45}$ Idem. Corpos em evidência: cenas corpóreas antropomorfas rupestres em São Raimundo Nonato (PI). Revista Cordis. História, Corpo e Saúde, n. 7, jul./dez. 2011, p. 219-245.

${ }^{46}$ LE BRETON, David. Adeus ao corpo. Antropologia e sociedade. Campinas: Papirus, 2003.

${ }^{47}$ SCOTT, Joan. Gênero: uma categoria útil de análise histórica. Educação \& Realidade, v. IS, n. 2, jul./dez. 1990.

${ }^{48}$ LOURO, G. L. Gênero, sexualidade e educação: uma perspectiva pós-estruturalista. 15ª . ed. Petrópolis: Vozes, 2013.
} 
de 1980, onde os temas irão tornar tão múltiplas quanto as suas arqueologias na procura da contextualização, da interpretação, ou mesmo na postura crítica do cientista ${ }^{49}$.

O modelo de pensar e analisar o histórico culturalismo alemão e em seguida o inglês, como teoria da arqueologia procura responder, desde o final do século XIX, aos problemas de ordenação da cultura material, especialmente nos seus aspectos evolucionistas e difusionistas. Enquanto a teoria processualista inglesa e a nova arqueologia norte-americana, surgidas na década de 1960 e têm como base a procura por leis gerais ou regularidades no comportamento humano, e em sua adaptação ao meio, em qualquer época ou lugar. Elucidado, principalmente, nos trabalhos de Clarke e Lewis Binford com a maior preocupação de uma arqueologia científica e a mais positivista possível, que quer saber como essas materialidades se comportam sistemicamente de cultura em cultura, o que não diferia muito de seus predecessores histórico-culturalistas ${ }^{50}$.

O pós-processualismo, por sua vez, surge na década de 1980 na Inglaterra e vai encontrar no estudo do pensamento, e não só da cultura material, sua principal motivação para a investigação arqueológica. Embasado nos trabalhos de lan Hodder, Michael Shanks e Christopher Tilley, esta corrente teórica vai ser uma corrente de diversos segmentos contrários ao processualismo, tendo como bons pensadores sociais como Karl Marx, Antoni Giddens, Michael Foucault, Pierre Bourdieu e de instrumentais teóricos como a hermenêutica ou a fenomenologia.

Assim sendo, parece-nos, que o principal questionamento feito pelos pós-processualistas é porque, ou, mais especificamente, para quem ou para que, a cultura material age sobre as culturas humanas. Dentro do viés da arqueologia histórica os trabalhos envolvendo categorias mentais, tais como os de James Deetz em respeito ao nascente pensamento georgiano, ou as abordagens sobre outras categorias intangíveis como ideologia, gênero, identidade e poder vão ser os expoentes dessa corrente ${ }^{51}$. Assim é sucinto e necessário o este desenvolvimento das escolas na arqueologia para entender como surgiram os debates sobre gênero e identidade nessa disciplina.

O filósofo Robin Ceorge Collingwood explicita a construção dessa conjectura no passado, a tentativa de leitura do passado. Afirma o autor que:

Se dois historiadores desse separadamente uma reposta a pergunta Que espécie de acontecimentos sucederam, ou podem ou devem suceder na história", as suas respostas seriam extremamente diferentes se um deles pensasse habitualmente num acontecimento como algo que levasse uma hora e o outro objeto, como algo que levasse

\footnotetext{
${ }^{49}$ COSTA, Diogo M. Algumas abordagens teóricas na arqueologia histórica. Ciência e Cultura, SP, v. 65. n. 2, 2013.

${ }^{50}$ COSTA, Claudia de Lima. Feminismos descoloniais para além do humano. Estudos Feministas, v. 22 n. 3, 2014 , p. 320

51 Ibidem.
} 
anos; e um terceiro, que concebesse um acontecimento como levando para uma de 1000 anos, daria seu turno uma outra reposta diferente. ${ }^{52}$

Boas $^{53}$ nos seus estudos cita a importância dos processos adaptativos dos grupos humanos para solucionar problemas do seu cotidiano, visando uma melhor integração ao meio ambiente. $\mathrm{O}$ autor afirma que as obras de arte aborígenes possuem um alto grau de habilidade, nos quais os elementos como simetria e ritmo são os principais critérios de análise dessas obras contidos na habilidade técnica.

Dessa forma, em vez de pensar-se em tradições, subtradições e estilos como unidade cultural de apenas um determinado grupo cultural, é interessante também pensar como opções artísticas e estratégias de um grupo cultural. No qual, adota-se um dado estilo em um local, sem necessariamente ser um novo grupo cultural, mas apenas por uma opção de escolha ${ }^{54}$.

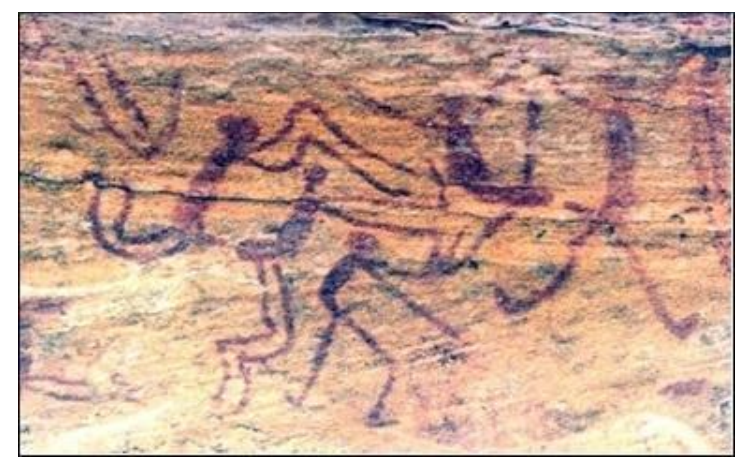

Figura 02: Cena do sexo grupal.

Toca do Baixão do Perna IV, Parque Nacional Serra da Capivara - PI Acervo dos autores.

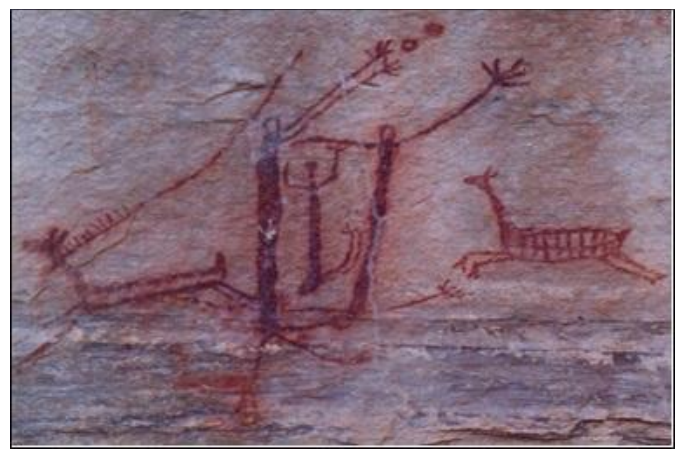

Figura 03:

Cena da representação da penetração de, supostamente, um homem com duas mulheres.

Toca do Pinga do Boi I, Parque Nacional Serra da Capivara - PI.

Acervo dos autores.

Assim como a penetração anal masculina, verificada em uma cerâmica peruana, datada de 600 anos depois da era cristã ${ }^{55}$, encontramos algumas cenas similares entre as do parque piauiense com datações entre 6 e 12 mil anos (Ver figura 4).

\footnotetext{
${ }^{52}$ COLINCWOOD, Robin G. Ciência e Filosofia: a ideia de natureza. Lisboa: Editorial Presença, 1986, p. 32.

53 BOAS, F. A formação da antropologia americana, 1883-1911: Antropologia. Tradução Rosaura Maria Cime Lima Eichenber. Rio de Janeiro: Contraponto/UFR], 2004.

54 JUSTAMAND, OLIVEIRA e COMES FILHO. As principais teorias acerca da arte rupestre: um estudo de caso. Revista Interdisciplinar Encontros das Ciências, v.3, 2020, p.993-1012.

55 TAYLOR, Timothy. A pré-história do Sexo. Quatro milhões de anos de cultura sexual. Trad. Ana Gibson. Rio de Janeiro: Campus, 1997
} 


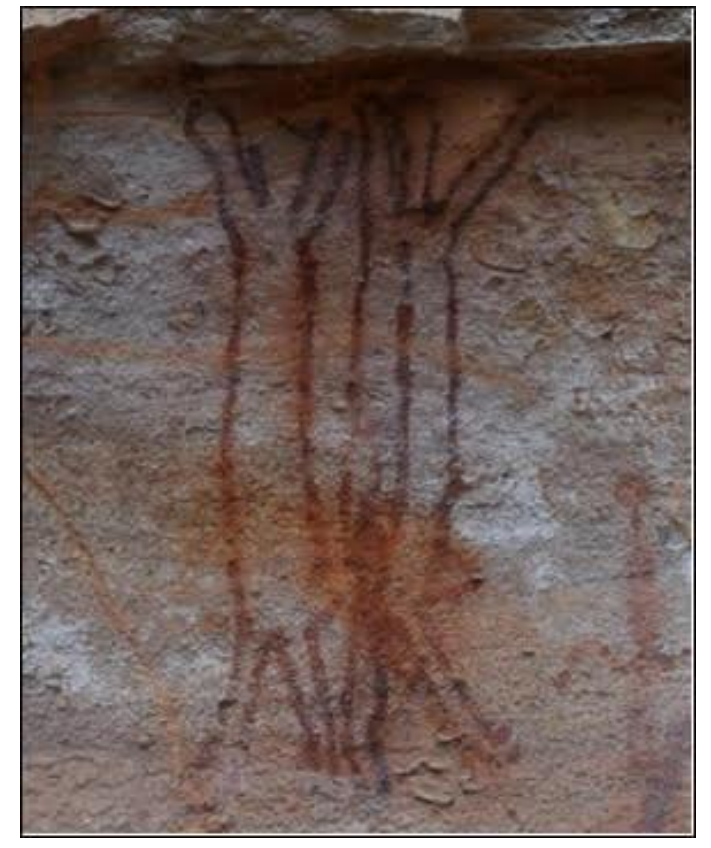

\section{Figura 04:}

Cena da penetração/relação sexual entre dois antropomorfos, provavelmente, representações de dois homens.

Toca Boqueirão da Pedra Furada,

Parque Nacional Serra da Capivara - PI.

Acervo dos autores.

Encontram-se vestígios da temática sexual, na Austrália, na Nova Caledônia e na Itália ${ }^{56}$ e na Rússia ${ }^{57}$. Parece-nos que era condição sine qua non da nossa espécie, desde milhões de anos atrás, publicar, deixando marcadas nas rochas para a eternidade, suas reflexões e ideias sobre as suas formas e relações com as práticas sexuais, problematizando outra concepção de corpo, sexo e gênero diferente da nossa era. Assim, em muitas cenas como as de caça e rituais evidenciamos marcações de ordem sexual. As pinturas de cenas sexuais, tais marcações ficam evidentes, como meio de comunicação destas relações, observando assim possíveis posições sociossexuais que são reverberações da organização social desses grupos humanos ${ }^{58}$.

A temática sexualidade não está direcionada às relações entre os grupos humanos, mas o registro rupestre aponta a possibilidade de relações entre eles e os não-humanos, a partir da observação de recorrências rupestres no $\mathrm{PNSC}^{59}$. Destarte, o campo objetal da sexualidade transpassa as barreiras do binarismo de gênero e espécie, demonstrando uma multiplicidade de relações, podendo transpassar o discurso biológico, social, político ou econômico da matriz reguladora heterossexual, por meio dos estudos culturais com abordagens desestabilizadoras sobre gênero, sexo e sexualidade pautas dos estudos queers na

\footnotetext{
${ }^{56}$ DUBAL, Leo. The art of representation of sexual intercourse. Revista Expression, Sexual imagens in prehistoric and tribal art, n. 15, mar. 2017, p. 14-18.

${ }^{57}$ MYKHAILOVA, Natalia. Sex as transition between worlds in deer hunting society (mythology and rock art). Revista Expression, Sexual imagens in prehistoric and tribal art, n. 15, mar. 2017, p. 58-68.

${ }^{58}$ JUSTAMAND, M. e OLIVEIRA, G. F. Os falos nas pinturas rupestres do Parque Nacional Serra da Capivara/PNSC-PI/Brasil. Brazilian Journal of Development, v. 7, p. 50576-50596, 2021.

${ }^{59}$ Ibidem.
} 
qual apontam para novas possibilidades ${ }^{60}$. Esse desenho rupestre, ao que nos parece, de zoofilia encontramos similares no PNSC no qual agrega folego para gerar a desestabilidade do discurso de sexualidades intra espécie, além de apontar para necessidade de uma revisão teórica e metodológica para a compreensão de gênero e sexualidade a partir dos estudos arqueológicos (ver figura 5).

Lins $^{61}$ afirma que baseado em suas pesquisas que entre os grupos caçadores e coletores, havia a exogamia, ou seja, eles copulavam com pessoas de fora do seu grupo. Ocorriam festas e encontros periódicos entre eles. Lins ${ }^{62}$ reitera que esses eventos proporcionavam uma série de situações, tais como as ampliações das redes políticas, econômicas, sociais, mas também as sexuais. Justamand ${ }^{63}$ fundamentado em suas pesquisas de campo em que as representações de muitos antropomorfos juntos e, possivelmente, "comemorando" algo são encontradas no PNSC (ver figura 6).

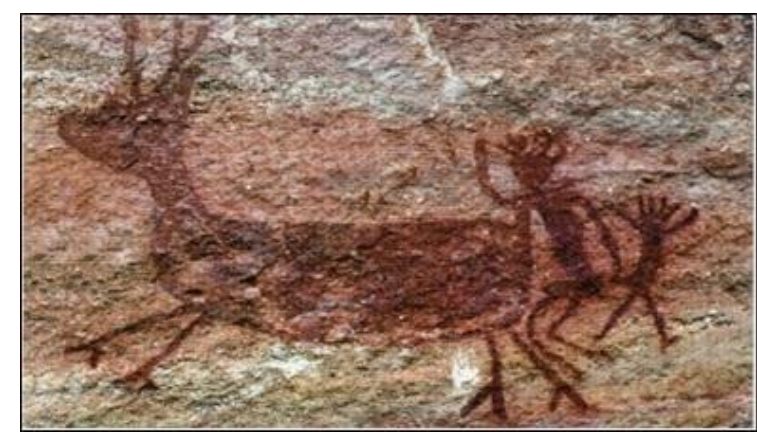

Figura 05:

Cena da representação de dois homens com um animal, com a, possível, penetração de um animal por um desenho de homem, e a penetração, aparentemente, de duas figuras de sexo masculino. Mostra ainda que uma representação masculina segura o falo de outra.

Toca do Caldeirão dos Rodrigues,

Parque Nacional Serra da Capivara - PI.

Acervo dos autores.

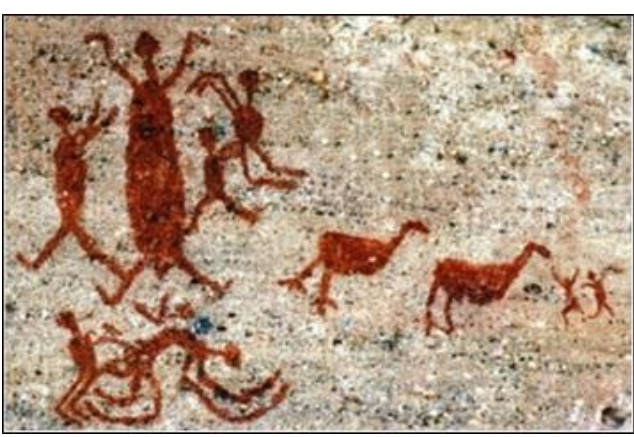

Figura 06:

Cena da penetração com animais e outras pessoas perto. Toca da Vereda do Juvenal, Parque Nacional Serra da Capivara - PI. Acervo dos autores.

No mundo ancestral indo-europeu-asiático, muitos artefatos atribuídos a representações de mulheres foram esculpidos em marfim ou em pedra analisados dentro do nosso universo cultural simbólico ocidental. O desafio de analisar uma obra de arte não ocidental a partir de uma perspectiva

\footnotetext{
60 BUTLER, Judith. Problemas de gênero: feminismo e subversão da identidade. Rio de Janeiro: Civilização Brasileira, 2003.

61 LINS, Regina Navarro. O livro do amor. Vol. 1. Da pré-história à renascença. Rio de Janeiro: Best Seller, 2012.

62 Ibidem, p. 75.

63 JUSTAMAND, Michel. O Brasil desconhecido: as pinturas rupestres de São Raimundo Nonato - Piauí. Rio de Janeiro: Achiamé, 2010.
} 
ocidental pode acarretar uma série de problemas de intepretação, essa sempre é subjetiva e está associada ao contexto do observador, gerando uma série de possibilidades ${ }^{64}$. É possível comparar as experiências das pessoas do presente com as pessoas das sociedades pretéritas?

Dentro desse contexto, a perspectiva atribuída a essas esculturas se espalhou por toda essa região, logo, tais representações poderiam destacar prováveis traços culturais e sexuais femininos. Como realizar essa interpretação dentro do campo da arte rupestres? Um exemplo, análise de grafismos com a forma de um antropomorfo, os elementos que devem ser buscados no desenho: cabeça, eixo da coluna vertebral, membros superiores e inferiores e uso de equipamentos manuais ou adereços, com esses elementos são possíveis identificar um grafismo com formatação humana.

Todavia, existem estatuetas, que não demonstram com clareza uma configuração clara da sexualidade, deixando a impressão de serem o que hoje nomearíamos como andróginas ${ }^{65}$. Os artesãos ancestrais investiam suas qualidades técnicas para produzir essas imagens, tinham seus propósitos, obviamente, tanto na criação das representações de mulheres, quanto nas representações de androginia (ver figura 7).

Sobre as produções de pinturas, estatuetas e esculturas, de modo geral, no antigo Egito, por exemplo, suas características de representatividade das mulheres aparecem com sinuosas curvas, demarcando as dimensões de suas nádegas e cinturas com seus seios bem desenvolvidos ${ }^{66}$.

Timothy Taylor aponta que as artes rupestres contribuíam para a ampliação da compreensão, reconhecimento e discussão sobre como eram as relações entre as pessoas naquele período histórico. Indica que as representações de vulvas pintadas nas rochas, datadas de mais de 12 mil anos atrás, especialmente nas cavernas europeias, poderiam ter conotações eróticas e ou rituais. Indica a existência de bastões "fálicos", alguns com representações nítidas de pênis, às vezes mais de um no mesmo objeto. Eram feitos de marfim, em sua maioria. Já a função desses objetos poderia ser de consolo, inserção vaginal, oral, anal, entre outras ${ }^{67}$. As inscrições no parque brasileiro apresentam tais conotações sexuais em seus desenhos nas rochas (ver figura 8).

\footnotetext{
${ }^{64}$ CUIDON, Niède. Arte Rupestre: Uma síntese do procedimento de pesquisa. Arquivos do Museu de História Natural. Belo Horizonte: UFMG, v. 6-7, p. 341-352, 1984.

${ }^{65}$ ADOVASIO, PACE, op. cit.

${ }^{66}$ DOMÍNCUEZ-RODRICO, Manuel. El origem de la atracción sexual humana. Madrid: Akal, 2011.

${ }^{67}$ TAYLOR, op. cit.
} 


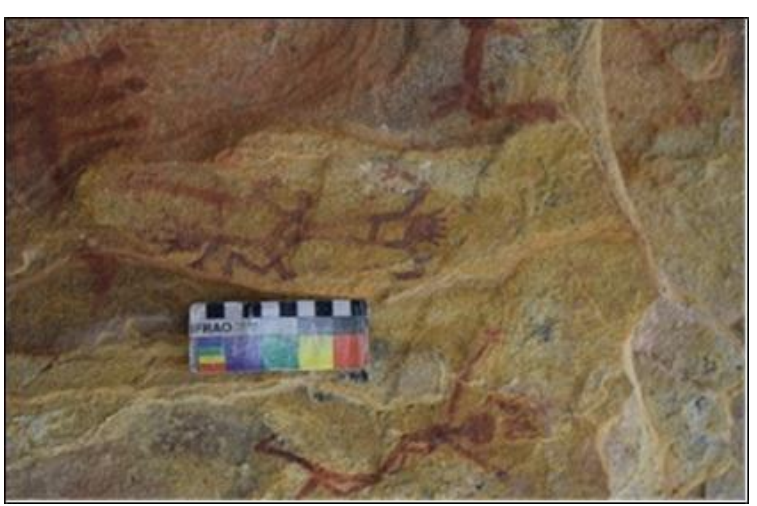

Figura 07:

Cena do Sexo com pessoas do mesmo sexo, provavelmente, representações de duas mulheres.

Toca do Pinga do Boi, Parque Nacional Serra da Capivara - PI. Acervo dos autores.

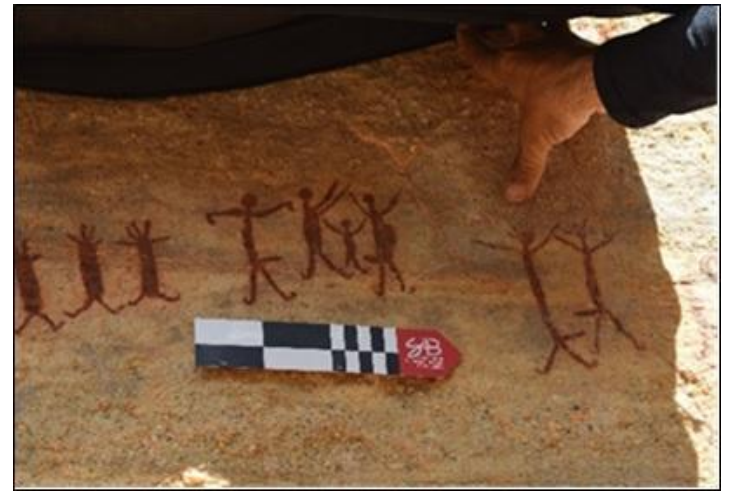

Figura 08:

Cena de falos eretos e de homens com seus falos um de frente para o outro.

Toca do Sítio do Meio, Parque Nacional Serra da Capivara - PI. Acervo dos autores.

Baseados nos vestígios deixados por humanos pretéritos, imaginamos que outras relações sociais/sexuais eram possíveis, diferente do que muitas pessoas pensam, devolvendo a complexidade da sociedade ao passado, presentes em suas relações com a natureza e no grupo social. Mas, afinal de contas, o que se idealiza sobre os costumes ancestrais? Se concebe que os nossos parentes mais antigos tinham práticas sexuais que poderiam ser consideradas, contemporaneamente, comuns à maioria dos sujeitos, no que tange as relações entre sexos opostos. Todavia, como visto, outras práticas sexuais que são variações da sexualidade humana, como a homossexualidade e a zoofilia podem ser problematizadas ${ }^{68}$. Outra questão que deve ser observada com cuidado analítico são as práticas sexuais que envolvem crianças e animais, uma vez que, as ciências contemporâneas classificam tais práticas correlacionadas a questões de ordem patológica. Desse modo, para esse último ponto, faz-se necessário um maior cuidado analítico, para que se evite anacronismos.

As temáticas e cenas de sexos são elementos presentes nos três estilos da subtradição Várzea Grande, isso demonstra que a questão da sexualidade era uma temática com grande relevância nas sociedades pré-coloniais naquela região, inclusive algumas imagens apontam a possibilidade de violência sexual cometida, zoofilia e cenas de gravidez, tanto no estilo Serra da Capivara quanto no estilo Serra Branca.

\footnotetext{
${ }^{68}$ JUSTAMAND, OLIVEIRA, op. cit., 2021
} 
De acordo com Prous:

'O 'complexo Serra Talhada' substituiria aos poucos a variedade 'Serra da Capivara'. As cores são o vermelho, o amarelo e o preto. As figuras são miniaturizadas (menos de 10 $\mathrm{cm}$ ), os antropomorfos se agrupam em cenas de atuação coletiva, incluindo violência e sexo. Parece que teria hábito a uma certa evolução cronológica, por exemplo, uma tendência à miniaturização das figuras, mas há ainda pouco dados referentes à cronologia; as gravações parecem tão antigas quanto as pinturas, e correspondem ao mesmo estilo". 69

A particularidade da arte rupestre do PNSC consiste em ser o maior enclave de sítios do mundo, uma permanência de ocupação de territórios de milhares de anos e uma diversidade temáticas impressionante, ressaltando a temática da sexualidade, especialmente, pela existência de recorrências de relações sexuais entre gênero igual e diferente, relações de zoofilia ${ }^{70}$ e cenas de estrupo ou violações sexuais ${ }^{71}$.

Ao estudarmos as técnicas corporais sexuais através de imagens, deixadas em formações rochosas, contribuímos para o entendimento de parte da vivência de nossos ancestrais, e, então, logo depois, com a definição da cidadania cultural no contexto piauiense. Pois, parece-nos, que ser cidadão é ter consciência e controle do próprio processo, projeto e trajetória de formulação e reformulação identitária, o que passa pelo pleno conhecimento das práticas passadas de nossos antecessores.

\section{O que emana do parque}

Atualmente estão catalogados 1.335 sítios arqueológicos no local, 184 sítios com vestígios cerâmicos, 946 sítios de pinturas rupestres, 206 sítios de pinturas e gravuras e 80 sítios de gravuras ${ }^{72}$. Esses locais, a nosso ver, abrangem muito mais do que a catalogação pragmática, marcação de tamanho e cores dessas imagens, pensamos que nelas estão contidas histórias a serem reveladas e discutir possíveis temáticas, a partir das pinturas e cenas, abrem possibilidades de descentralizar as metodologias de classificação e discursos das "verdades arqueológicas" até então disseminadas.

\footnotetext{
69 PROUS, André. Arqueologia Brasileira. Brasília: Editora Universidade de Brasília, 1992, p. 523.

70 JUSTAMAND, OLIVEIRA, op. cit., 2021.

71 Ibidem.

${ }^{72}$ GUIDON, Niède. A Fundação Museu Homem Americano e o Parque Nacional Serra da Capivara: um relato sucinto de quatro décadas de pesquisas. In: PESSIS, Anne-Marie; GUIDON, Niède; MARTIN, Gabriela. Os Biomas e as Sociedades Humanas na Préhistória da região do Parque Nacional Serra da Capivara. São Paulo: A\&A Comunicação, 2014, vol. A, p. 26-44. GUIDON, Niède. O Pleistoceno Superior e Holoceno Antigo no Parque Nacional Serra da Capivara e seu entorno: as ocupações humanas. In: Ibidem, vol. II-B, p. 444-452
} 
O estudo da arqueologia queer e de gênero para compreender o corpo, ao se distanciar das perspectivas vitorianas e colonizadas ${ }^{73}$ que normatizam, disciplinam e os docilizam, propõe a descoberta de compreensão das performances menos afetadas pelo anacronismo, considerando as mudanças culturais do governo dos corpos durante as descontinuidades tempo-espaciais que podem ser percebidas estudos arqueológicos ${ }^{74}$. Histórias que têm importância para se refletir o hoje ${ }^{75}$, inclusive no que tange os processos de escolarização.

Sabemos que pesquisas anteriores já contemplaram temáticas próximas as que estamos a apresentar nesse texto.

Por esse motivo elencamos algumas a seguir:

Gabriela Martin, uma das pesquisadoras mais antigas da FUMDHAM, que tem acompanhado os trabalhos desde os anos 70, do século passado, já abordou a temática do amor. Publicou um dos primeiros trabalhos sobre as pinturas rupestres do parque tratando de amor, violência e solidariedade ${ }^{76}$.

As pinturas rupestres do PNSC seriam referências no entendimento da sequência de ocupação humana no Nordeste naquela época. Esses humanos deixaram marcas, um tanto decifráveis, nas rochas. Algumas compondo cenas representativas das ações humanas. Encontramos nas rochas figuras com cabeças ornadas, lutas sociais e grupais. E muitas vezes, aparecem o sexo, ilustradas pelas genitálias indicado pelo pênis, para os homens, tanto ereto quanto em descanso e o círculo abaixo das pernas para indicar as vulvas, demarcação, em alguns casos, das mulheres ${ }^{77}$.

A temática da sexualidade se tornou alvo de debates, mesmo que de forma branda, em poucos manuais e artigos, apesar de sua presença significativa nas inscrições do PNSC. No livro Comunicare Educar no território brasileiro: uma relação milenar foi tratada a questão, especialmente, comparando com as imagens de outras partes do país ${ }^{78}$.

A investigação sobre a mesma temática teve outros desdobramentos publicados em revistas ou livros. Um deles foi O Brasil desconhecido: as pinturas rupestres de São Raimundo Nonato - Piauí, onde se expôs os gestuais rupestres com cenas de pedofilia, penetração, excitação masculina coletiva e sexo grupal. Outro desdobramento ocorreu com a publicação da temática relacionada aos falos eretos e em grupos.

\footnotetext{
${ }^{73}$ FOUCAULT, op. cit.

${ }^{74}$ GONTIJO, SCHAAN, op. cit; COLLING et al, op. cit.; GUIDON, op. cit., 2014 a.

${ }^{75}$ CUIDON, op. cit., 2014a.

${ }^{76}$ MARTIN, op. cit.

77 PROUS, André. O Brasil antes dos brasileiros. A pré-história do nosso país. Rio de Janeiro: Zahar, 2006; PESSIS, op. cit.

78 JUSTAMAND, M. O feminino rupestre em São Raimundo Nonato (Piauí): muito antes de 1500. Revista EDUCAmazônia Educação, Sociedade e Meio Ambiente, v. VIII, 2012, p. 121-135.
} 
Outros temas que se desdobraram e que ganharam certa visibilidade são as presenças de falos, vulvas e sexo com mulheres grávidas. Esses se tornam alvo de investimentos em pesquisas entre os anos de 2013 e 2015. Tais investimentos foram transformados em novas publicações ${ }^{79}$.

Pessis e Martin publicaram novas reflexões e incluíram entre essas ideias a discussão sobre a importância das artes rupestres para a história da arte brasileira. E em seus escritos atuais, lembram que muitas pinturas rupestres representam o movimento, ou seja, que nas cenas é possível notar o movimentar das reproduções. As autoras, apesar de discordarem das interpretações das imagens rupestres, indicam que há cenas de lutas, caças, muitos animais, danças e sexo. Sugerem que esses inscritos nas rochas, são bem representados e com riqueza de "interpretações" (dizem elas), além de terem uma técnica com traço leve e seguro.

A construção do conhecimento arqueológico também está inserida dentro desse contexto acadêmico, o substrato dos arqueólogos na leitura de um passado é a cultura material ${ }^{80}$. A partir da análise da cultura material em forma de vestígios e fatos arqueológicos, é possível conhecer o modo de vida dos grupos humanos do passado e do presente ${ }^{81}$.

A principal dificuldade em analisar as obras de artes pré-históricas é tentar compreender seu significado dentro de um contexto arqueológico, a perspectiva estética pode fornecer informações acerca seu designer e formatação, mas apenas pelo uso da semiótica podemos buscar uma interpretação e denotar um valor ou significado ${ }^{82}$.

A interpretação dos dados arqueológicos das sociedades pré-coloniais está associada à antropologia pré-histórica, que permite a investigação da estrutura política, econômica e social de uma sociedade. A arqueologia é uma ponte entre o presente e o passado ${ }^{83}$ (SHANKS e TILLEY ${ }^{84}$ ). Esta narrativa arqueológica do passado pode ser alterada a partir de dois fatores, como: 1) novas evidências arqueológicas descobertas e; 2) modificações na estrutura política (UCKO $\left.{ }^{85}\right)$.

\footnotetext{
${ }^{79}$ JUSTAMAND, M.; FUNARI, P. P. A.; ALARCÓN-JIMÉNEZ, A.; OLIVEIRA, G. F. Arqueologia do Feminino. A mulher não é só sexo na Serra da Capivara. O feminino nas pinturas rupestres em São Raimundo Nonato/PI. Embu das Artes: Alexa Cultural, 2017. ${ }^{80}$ Cultura Material: "Se a cultura material é definida de forma a abranger todos os meios precisos para o conhecimento de fins sociais a atingir, precisamos incluir, entre os últimos, desejos e propósitos que o Homo sapiens não compartilha com nenhum outro animal" (CHILDE, 1976, p. 74).

${ }^{81}$ HODDER, I. Interpretación en Arqueología: Corrientes actuales. Trad. Maria José Aubert e J.A. Barcelona. Editora Crítica, 1994.

${ }^{82}$ LAYTON, R. Antropologia da Arte. Tradução Abílio Queirós. Lisboa: Edições 70, 2001.

${ }^{83}$ De acordo com Albuquerque Júnior (2011, p. 40): "O campo historiográfico, como campo de produção do saber, está recortado por relações de poder que incidem sobre o discurso historiográfico. Ele é a positividade de um lugar no qual o sujeito se articula, sem, no entanto, se reduzir a ele".

${ }^{84}$ SHANKS, M.; TILLEY, C. Social Theory and Archaeology. Albuquerque: University of New Mexico Press, 1988

85 UCKO, P. Introduction. In: UCKO, P. (ed) Theory in Archaeology: A World Perspective. Londres: Routledge, 2005, p. 1-24.
} 


\section{Últimas palavras}

O nosso posicionamento como autores é o de que o diferencial do presente trabalho foi o de juntarmos as temáticas sociais e/ou da sexualidade grafadas no período rupestre, numa mesma exposição e sequência de interpretação e análises. Reconhecemos que essa proposta pode não apresentar a totalidade de informações e conhecimento que o tema provém. Todavia, ressaltamos aos leitores que outros estudos foram publicados ao longo dos dois últimos anos, sendo estes indicados para uma maior compreensão dos desdobramentos da expedição. O texto aqui é um apontamento para que os nossos leitores tenham uma ideia, mesmo que fragmentada, do universo afetivo social e sexual pintado nas rochas do PNSC. Produções que foram ali registradas que podem atingir mais de 10 mil anos ${ }^{86}$ e que muito ainda há para ser descoberto, analisado e apresentado à sociedade civil e científica.

Nesses escritos nos preocupamos em apresentar um aperitivo das cenas rupestres com a temática da sexualidade ou social, do que está à disposição nas rochas do PNSC. Sabemos da existência de muitas outras cenas e temas a serem abordados. Sem esquecer, evidentemente, muitas observações ainda devem ser realizadas junto as marcas registradas nas rochas por nossos parentes ancestrais.

Tomamos como certo que nossos ancestrais ao registrarem práticas sexuais e ou sociais variadas, em suas artes, demonstram que lidavam, ao que nos parece, com muita naturalidade, com os seus corpos e, também, os seus afetos, por mais diferentes e diversos que fossem esses desejos e ações sexuais. Mais do que tudo que a sexualidade, em todas as suas variantes, não era reprimida ou escondida, ao que nos faz indicar, pelas cenas, afinal as pinturas rupestres estavam ali para todos verem e todos tinham acesso livre.

Lembramos, finalmente, que os sítios arqueológicos do PNSC costumam ser abertos, não precisando de esforços especiais para realizar as visitações, e são de fácil acesso, então, sugerimos, visitem o parque! Conheçam mais!

\footnotetext{
${ }^{86}$ PESSIS, CISNEIROS, MUTZENBERG, op. cit, p. 19-33.
} 